\title{
Design of a Virtual Reality Software to Promote the Learning of Students with Dyslexia
}

\author{
Sonia Rodríguez-Cano*D, Vanesa Delgado-Benito, Vanesa Ausín-Villaverde and Lucía Muñoz Martín \\ Faculty of Education, Didactics and School Organization, University of Burgos, Castilla y Leon, \\ 9005 Burgos, Spain; vdelgado@ubu.es (V.D.-B.); vausin@ubu.es (V.A.-V.); 1mm1005@alu.ubu.es (L.M.M.) \\ * Correspondence: srcano@ubu.es; Tel.: +34-699-34-7748
}

\begin{abstract}
The research conducted is part of the European project Erasmus+ FORDYSVAR, whose main objective is to contribute to the educational inclusion of students with dyslexia, aged between 10 and 16 years old, through the use of technology, specifically virtual reality (VR), to improve the access, participation, and educational achievement of students with this learning difficulty. This is a qualitative and interpretative study with a descriptive character. The objective of this work is to design a VR application that contributes to the learning of students with dyslexia based on user-centered design as a methodology. The developmental lines to be addressed in the application have been defined, the features to be included have been determined, and the activities that make up the software have been designed. All this is based on the analysis of the needs and interests of the end users (students with dyslexia) as well as the vision of professionals (teachers and dyslexia intervention specialists). The results obtained allow us to conclude that VR technology is an interesting avenue of treatment, as it offers a ludic, safe, controlled, and motivating environment for students with dyslexia.
\end{abstract}

Citation: Rodríguez-Cano, S.; Delgado-Benito, V.;

Ausín-Villaverde, V.; Martín, L.M. Design of a Virtual Reality Software to Promote the Learning of Students with Dyslexia. Sustainability 2021, 13, 8425. https://doi.org/10.3390/ su13158425

Academic Editors: Roberto Baelo and Marc A. Rosen

Received: 26 April 2021

Accepted: 19 July 2021

Published: 28 July 2021

Publisher's Note: MDPI stays neutral with regard to jurisdictional claims in published maps and institutional affiliations.

Keywords: dyslexia; educational technology; virtual reality; FORDYSVAR

\section{Introduction}

The etymological origin of the word dyslexia comes from the Greek roots $d y s-$ meaning difficulty, and lexia, meaning reading, referring to the difficulty in reading, a term coined in the late 1880s [1].

The International Dyslexia Association was a pioneer in providing a definition that allowed the delimitation of the concept at the international level, defining dyslexia as a specific learning difficulty (SLD) of neurobiological origin, characterized by the presence of difficulties in the accuracy and fluency in the recognition of (written) words and by a deficit in decoding (reading) and spelling skills. These difficulties are usually a consequence of a deficit within the phonological component of language, and occur unexpectedly, as other cognitive skills are normally developed and the reading instruction is adequate. As secondary consequences, some reading comprehension difficulties can manifest and the reading experience can be reduced, which can hinder vocabulary growth and general knowledge [2-4].

From the clinical point of view, dyslexia is also framed in the context of learning disorders, although more emphasis is placed on its nature as a dysfunctional behavioral and cognitive disorder. Thus, the International Classification of Diseases (ICD-10) conceptualizes dyslexia as a specific reading disorder whose main characteristic is a specific and significant deficit in the development of the ability to read, which cannot be explained by the intellectual level, visual acuity problems, or inadequate schooling [5].

According to the Diagnostic and Statistical Manual of Mental Disorders (DSM-V), dyslexia is found in the subcategory of neurodevelopmental disorders denominated "specific learning disorder", referring to a pattern of learning difficulties characterized by problems with accurate or fluent word recognition, misspelling, and poor spelling ability [6]. Consequently, dyslexia can be defined as a specific learning disorder in reading 
and writing, which has a persistent and specific nature, whose origin derives from a neurodevelopment alteration and is characterized by the difficulties the person has when recognizing certain words in a fluid and precise manner, together with decoding and spelling skills, due to a deficit in the phonological component of language and affecting the field of reading [7-11].

Its prevalence worldwide is estimated at between 5\% and 15\%. In Spain, it has an impact on primary and secondary education at a percentage between $5 \%$ and $10 \%$ of the student body [12,13].

It is a lifelong condition; however, it is manageable with intervention through remedial and adaptive therapy. The traditional methods currently used for the treatment of this learning disorder are mostly paper-and-pencil methods, which tend to be monotonous and very demanding, with high dropout rates in many cases.

In this regard, multisensory approaches have shown increased adherence to treatment and rather promising results [14,15].

Recently, some approximations have been carried out in the field of educational technology for the treatment of dyslexia $[16,17]$. Among the advantages that technologies can provide within the treatments, we can find the following: they offer safe and controlled environments, generate higher motivation [18], enable interactivity, provide immediate feedback, and contribute to the improvement of skills related to visual processing and working memory $[16,19,20]$.

The richness of technology lies in the fact that it presents information through multimedia elements (audio, text, images, or videos), having the possibility of storing and transferring, combining the resources, or even making transformations. This is considerably beneficial for the students' individual needs, contributing to the treatment of dyslexia [21-23].

In this regard, research has been carried out using technological tools to facilitate the intervention in specific learning disorders in reading and writing [9,24-28].

Traditional speech therapy requires perseverance and exhaustive dedication, and this causes a large number of dropouts in the therapeutic process necessary for the improvement of this learning difficulty. For this reason, it is crucial to develop new intervention approaches that can help students with dyslexia in a more fun way and with a higher compromise from them [29]. In this case, virtual reality (VR) can fill this gap, as several studies propose that this technology is the only one that includes immersion, presence, interaction, transduction, and conceptual change [30-32]. Other potentialities are that it is a safe, flexible tool with high adherence rates [33] and with the possibility of offering a multisensory approach [15], being considered one of the most promising treatment avenues in the field of dyslexia [14].

\subsection{Neurobiology of Dyslexia}

In the reading process, the circuits that encode visual information or the sounds of words positively favor oral memory. Empirical evidence proposes that a part of the neurons is necessary for the act of learning to read to be more effective and to respond to more letters and words; this region is located in the left temporal lobe, called "the brain's letterbox". It is a small region of the visual system that comprises the brain pathways of reading and phonological and lexical learning and is activated when we read; furthermore, it is activated to a greater degree when faced with written words than when faced with other visual stimuli [34].

In expert readers, the two neural pathways are activated in parallel: the phonological, which allows us to pronounce new words and try to access their meaning, and the lexical, which allows us to retrieve the meaning of known words [35]. Therefore, as the child automates reading, the phonological decoding of the word into letters becomes a simultaneous process, recognizing words more quickly and interpreting the meaning of written words.

In dyslexic individuals, neuroimaging reveals abnormal activation in the left occipitotemporal cortex, left inferior frontal gyrus, or inferior parietal lobe, which are the brain regions involved in the phonological representations, phonological decoding, and attention [36]. 
Thus, the cause of learning difficulties may lie in a deficit affecting synaptic connections and neural connectivity [37-39]. Therefore, it can be said that dyslexia is a disconnection syndrome; the worse the functional connectivity between these regions, the worse the results in reading and other phonological tasks. That is, it is a deficient construction of the neurological structure in learning.

In dyslexic children, there is a natural instinct to interpret the word as a whole; this means that by focusing the attention on the whole word, the information saturates the child's working memory and activates a region of the right hemisphere that is less efficient in the reading process [40].

The most recent findings suggest the relationship between dyslexia and the alteration of chromosomal regions in which the genes called DYXICI, KIAA0319, DCDC2, and ROBOI could be involved [41]. These findings give evidence of the importance of the hereditary factor, highly predictive of the presence of disorders [42].

\subsection{Virtual Reality and Dyslexia}

Currently, educational technology is conceived as a resource that facilitates the inclusion and integration of students, becoming a powerful didactic tool that is integrated into the teaching-learning processes, achieving the acquisition of skills and competences and strengthening the abilities, performance, and students' educational achievements [43]. In addition, it allows bringing content closer, increasing motivation, stimulating and reinforcing student learning, bridging the educational contents with entertainment, and encouraging the acquisition of knowledge and generating curiosity [44].

Technology can offer solutions for the field of special educational needs [45], with a growing interest in supporting the inclusion of people with learning difficulties such as dyslexia $[27,46,47]$.

Several research projects have demonstrated that, among students having curricular difficulties, the use of technology contributes to the improvement of aspects as motivation, cooperation, and attention [48-50].

In this respect, virtual reality (VR) is one of the emergent technological tools, and its fame is increasing in relation to its application in the educational field [30].

From a technological and conceptual perspective, it can be defined as a combination of high-quality computing, computer interfaces, graphics, sensor technology, and networks, which allows the user to be immersed and to interact and experiment in real time an artificial three-dimensional (3D) environment, which represents real-life situations or others [51]. At its inception, virtual reality was applied through the use of computers, calling the one using external devices (headphones, gloves, speakers) immersive and the one not requiring the full concentration of the user non-immersive, such as computer programs where the interaction was through a keyboard or a mouse [30].

Today, due to its combination with digital mobile devices and the advance of this technology, it is difficult to understand VR as something non-immersive. It could then be defined as the technology that allows the user, through the use of a headset, to dive into three-dimensional scenarios in the first person and at 360 degrees [52]. This encourages the user to feel immersed inside the aforementioned scenarios, ceasing to see the place where they are located and to start seeing and interacting with a different reality and the elements that compose it.

VR technology applied to the educational field can facilitate constructivist learning, provide alternative learning opportunities, enable the collaboration among students beyond the physical space, and increase motivation and interest, as well as the development of the digital competence $[53,54]$. The versatility offered by this technology makes it adaptable to different contexts, one of them being learning difficulties, allowing these tools to become very useful elements to adapt content and improve student motivation [55-57].

The main characteristics contributing to its effectiveness are [19]:

- Immersion (physical perception of being present in a world that is not physical).

- Presence (bridge between reality and the virtual world). 
- $\quad$ Transduction (the user accesses the virtual stimulus).

Within the technological field, VR can make important contributions to the treatment of dyslexia, since it offers more playful environments that can improve adherence to treatment, as well as safe and controlled environments in which failure to make a mistake does not have negative consequences for the learner. Furthermore, it gives immediate feedback and can have high levels of interactivity [19] together with the possibility to offer a multi-sensorial approach [15], being considered as one of the most promising treatment options in the field of dyslexia [14].

Currently, few are the investigations carried out on dyslexia treatment and VR [46]. In this respect, to lay firm foundations for the treatment and rehabilitation of people with dyslexia through VR, more scientific research supporting the effectiveness of these interventions is needed [55-57].

The current investigation aims at contributing to the educative inclusion of students with dyslexia through the use of technology, specifically by means of the development of a virtual reality software through a multi-sensorial approach, using kinesthetic, visual, hearing, and tactical channels to contribute to the increase of memory and learning for people with dyslexia. All this focuses on achieving higher motivation and interest and contributes to the improvement of the effectiveness of traditional treatments.

\subsection{Erasmus+ European Project "FORDYS-VAR"}

FORDYS-VAR (Fostering inclusive learning for children with dyslexia in Europe by providing easy-to-use virtual and/or augmented reality tools and guidelines) is a European Project Co-funded by the Erasmus+ Program of the European Union under the project 2018-1-ES01-KA201-050659. FORDYS-VAR. This project was granted in 2018 by the Spanish Service for the Internationalisation of Education (SEPIE) with a total fund of $€ 367.544,00$ for the years 2018-2021 [58].

The current investigation is contextualized within the framework of the European project Erasmus+ FORDYSVAR, whose focus is transnational and whose coordination is performed from the University of Burgos, Spain, the Principal Investigator (PI) being the professor Sonia Rodríguez Cano. The consortium of the project is formed by different European partners:

- Spain: University of Burgos, K-Veloce consultancy, and the software company AR-SOFT.

- Italy: Eugenio Medea Scientific Institute.

- Romania: Bucharest's Association for Dyslexic Children.

This project is included within the Strategic Partnerships in the field of education, training, and youth (KA2), its main objective being to contribute to the educative inclusion of the students with dyslexia, of around 10 and 16 years of age, through the use of technology, specifically virtual reality (VR) and augmented reality (AR) to improve the learning access, participation, and achievements of students with this literacy disorder. The purpose is to generate a ludic, fun, and safe learning environment, creating a higher compromise toward treatment and improving their quality of life.

In particular, it addresses some of the horizontal priorities of Erasmus+, such as:

- Social inclusion, specifically supporting diversity and equal access to education for children with dyslexia.

- The use of the information and communication technologies (ICT) within learning environments to contribute to the access of students with dyslexia.

- Improving the teachers' skills, giving them the appropriate tools to adapt their educational devices for students with dyslexia.

As a result, in this project three intellectual products will be developed:

1. A toolkit:

Including software to integrate VR and AR in educational and pedagogical environments for school children with dyslexia. 


\section{E-book:}

With guidelines and good practices about dyslexia and the use of educational technology, together with the compilation of European regulations and the different approaches applied in the European Union on dyslexia.

3. White paper:

For the establishment of educational policies for children with dyslexia.

In this contribution, we present the results of the first intellectual product, in relation to the design and creation of a toolkit, specifically the ones related to the design of a VR software to contribute to the learning of students with dyslexia.

\section{Materials and Methods}

The current investigation is contextualized within the learning difficulties field, specifically dyslexia, which is the most common difficulty in the educational reality [59]. Because of this, this investigation intends to contribute to the inclusion of students with dyslexia through motivational learning strategies using technology, through virtual reality (VR) in particular.

The introduction of technology into the evaluation and intervention process can become a key element to improve learning efficacy, contributing to an improvement of visual skills and memory. Furthermore, it provides people with dyslexia with an improvement in their motivation, and it favors high levels of interaction.

This is a qualitative and interpretative study with a descriptive character, pursuing the discovery of cultural and social expressions through an interpretative process between observer and observee [60], appealing a closer and more detailed reflection of the subject in their own context, to get as close as possible to the signification of the phenomena [61]. All this is trying to interpret and capture particular and relevant meanings to those made in a metaphorical and conceptual manner [62].

\subsection{Objective}

The main objective stated in this paper is to design a virtual reality application that contributes to the learning of students with dyslexia based on a user-centered design methodology for the development of a video game that responds to the demands and/or needs of children with dyslexia.

To achieve this objective, a series of specific objectives is presented to represent each of the necessary steps to carry out:

- Define the developmental lines that need to be worked on in the application.

- Determine the characteristics that the virtual reality software needs to have on the basis of the analysis of the necessities and interests of users.

- Design the activities that integrate the RV software.

\subsection{Sample}

In this research project, there are diverse participants contributing to the making of the phases.

\subsubsection{Interest Groups}

The target group of the study who participated in the implementation of open interviews with the intention to know the most efficient interventions in the dyslexia field is presented in Table 1. 
Table 1. Interest groups (participant sample).

\begin{tabular}{ccccc}
\hline & Spain & Italy & Romania & Total \\
\hline Dyslexia intervention specialists & 3 & 3 & 3 & 9 \\
Families of students with dyslexia & 3 & 3 & 3 & 9 \\
Students & 3 & 3 & 3 & 9 \\
Teachers of students with dyslexia & 3 & & 9 & 3 \\
Total & 12 & 9 & 30 \\
\hline
\end{tabular}

This sample is made up of a total of 30 participants, 9 for each partner country of the project (Italy and Romania) and 12 in the case of Spain, as, apart from experts, 3 teachers have also been interviewed.

\subsubsection{Expert Review}

The intervention and developing areas upon which the activities have been designed have been reviewed by a group of experts in the Spanish context. The sample is made up of five experts among which there are three dyslexia specialists (speech therapist, therapeutic pedagogue, and language specialist psychologist) and two external professionals experts in virtual reality.

\subsubsection{Students with Dyslexia}

As has previously been explained, in the Spanish context, there have been interviews with a different and reduced group of students with dyslexia to get to know their opinion on the characteristics that the application should integrate in order to be attractive. In this case, the sample is made up of four minors with a dyslexia diagnosis, three boys and one girl, whose ages are between 10 and 16 and who are schooled in primary education and secondary education in ordinary educational centers from the province of Burgos (Spain).

\subsection{Procedure}

The present research uses a user-centered design methodology (UCD) as a model to implicate the participants in the phases in which a product is being developed, in this case, in the design and development of a virtual reality application to encourage learning in students with Dyslexia.

This user-centered design methodology aims at designing and creating products that people will find useful and usable, which means satisfying their needs bearing in mind their characteristics [63].

The UCD philosophy pursues a design of the software product that will predictably offer a satisfying user experience. Thus, the developed and designed application makes sense to the final user, who acquires a co-designer role [64].

User-centered design is based on a model of process that is divided into different phases or stages [65]. The first one, which is key for any UCD process, refers to the investigation and analysis of the users and their necessities in relation to the developing product.

It is important to know the people who will use the application, as well as their needs, in order to be able to give an adequate response bearing in mind their limitations and characteristics.

In this sense, involving students, teachers, dyslexia intervention specialists, and parents has been considered as a primordial requisite in this research for the design and development of the application.

In Figure 1, an outline of the procedure of the investigation is shown, bearing in mind the model of user-centered design (UCD). 


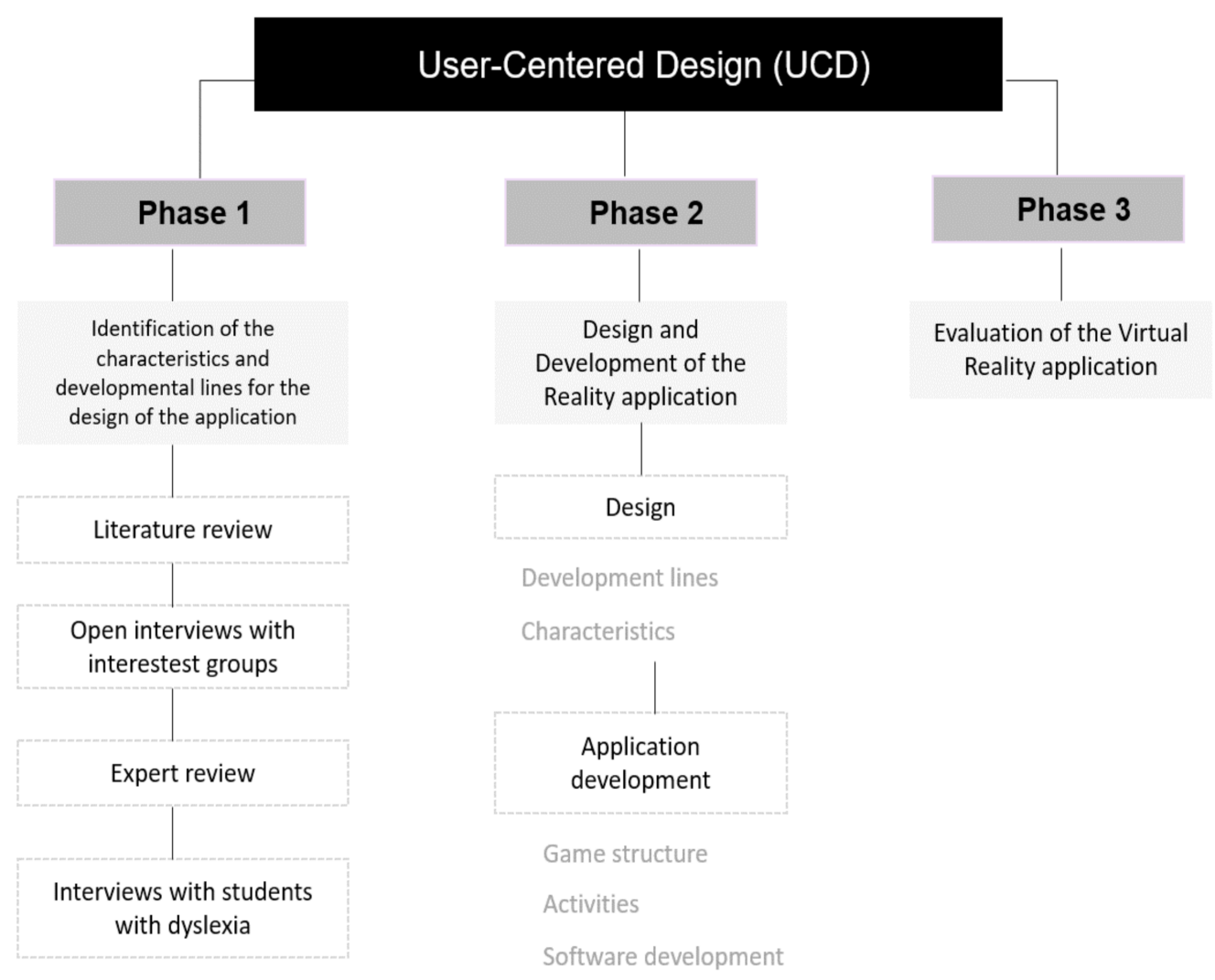

Figure 1. Model of user-centered design (UCD).

Attending to the outline of the present investigation, in this contribution, the first two phases are presented:

- Phase 1: Identification of the developmental lines and characteristics for the design of the application

- $\quad$ Phase 2: Design and development of the virtual reality application

The third phase, related to the evaluation of the virtual reality software, is still in the process of being made by the work team. In the software evaluation, both the users and the interest groups who have collaborated in the different phases of the design and development of the virtual reality will cooperate. This phase will be carried out by evaluating the reliability and validity of the instruments and the efficiency of the application developed in this project.

2.3.1. Phase 1: Identification of the Developmental Lines and Characteristics for the Design of the Application

The objective of this initial phase is to know the intervention axes necessary to work with children and young people with dyslexia through the application of virtual reality based on the involvement of the users.

To this end, first, a review of the literature on dyslexia and its treatment approaches was carried out, grouping the results into areas of interest. Subsequently, open interviews related to the field of dyslexia were conducted with the groups of interest: teachers and/or specialists in dyslexia intervention, students, and family members [29]. On the other hand, in the Spanish context, interviews were also carried out with students with dyslexia to find out their opinion about the characteristics that the application should have in order to be attractive to them [66].

These interviews were designed and agreed upon by the partners, making a first version in English and then translated into each language for administration. After the 
interviews were conducted by the partner countries, they were transcribed and translated into English for a joint analysis.

Following the analysis of the information gathered from the stakeholder interviews, ten categories were initially extracted in which students with dyslexia have more difficulties and therefore require more specific work. These categories were reviewed by dyslexia experts and agreed upon by the partners. Finally, seven lines of development were determined from which the activities that make up the virtual reality application have been designed: (1) phonological awareness; (2) working memory; (3) attention development; (4) perceptual-visual development; (5) perceptual-auditory development; (6) semantic, syntactic, and lexical development; and (7) motor development: laterality and directionality.

Thus, the information gathered in this first phase has made it possible to determine the lines of development necessary for the design of the activities, as well as to integrate the recreational components or characteristics to be taken into account in the design of the virtual reality application, understood as a game, in order to make it attractive to users.

\subsubsection{Phase 2: Design and Development of the Virtual Reality Application}

The work team of the University of Burgos, in coordination with the rest of the partners of the European consortium, has led the second phase corresponding to the design and development of the activities that make up the virtual reality application.

The application, aimed at students between the ages of 13 and 16, has been designed in a game or video game format, from a multisensory approach, showing dynamic environments, allowing different types of actions, and presenting information in different ways.

Based on the analysis and previous knowledge of all the partners, the themes and structure of the game were defined, and a first initial proposal was made, which later had to be modified and adapted to the budget available in the project financed for the development of the virtual reality software.

The technical development of the application (software) has been carried out by the company Arsoft (Augmented Reality Software S.L. Salamanca, Spain), a member of the working team of the European project Erasmus+ FORDYSVAR.

\subsubsection{Data Analysis}

In order to carry out the analysis of the data obtained in the interviews, content analysis was carried out, understood as a qualitative research technique aiming at converting symbolic behavioral phenomena into scientific data through the objective, systematic, and quantitative description of the manifest content of the communication or any other manifestation of behavior to facilitate an objective view of the fact [67].

The purpose of content analysis is to carry out a study of the manifest and then latent content applied to different topics and themes [60].

This type of analysis considers the presence of terms or concepts independently of the relationships between them, the most commonly used techniques being frequency lists, thematic identification and classification, and the search for words in context [68].

The criteria used to analyze the textual data from the different interviews were thematic, following the inductive method and trying to identify the central axes or main thematic categories in the content.

\subsection{Instruments}

A wide and varied collection of information has been necessary in order to achieve the proposed objectives and obtain conclusions.

In order to obtain information on the most effective interventions in the field of dyslexia, interviews were conducted with each of the stakeholders in the different countries of the European consortium (Spain, Italy, and Romania).

The design of the interviews is semi-structured, with relevant and open-ended questions, allowing the interviewee to give a freer, deeper, and more complete answer [69]. 
An interview has been designed for each of the groups of interest (teachers and /or specialists in dyslexia intervention, families, and students with dyslexia). After its initial design by the University of Burgos team, the content of the interviews was discussed and agreed upon by the other project partners until a final version in English was obtained. Subsequently, the interviews were translated into the languages of the participating European consortium (Spanish, Italian, and Romanian). The administration of the interviews was carried out by each country in their own language, and, after completion, they were transcribed and translated into English in order to perform the joint analysis of the content.

On the other hand, in the Spanish context, a semi-structured interview was designed consisting of seven open questions, formulated in a clear and simple way, in order to know the students' opinion about the characteristics that a virtual reality game should have according to their tastes and preferences. This interview was designed based on the existing literature and validated by doctors in education through the expert judgment technique [70].

Prior to conducting all the interviews, the participants were told what the FORDYSVAR project consisted of, what its objective was, and the reason for conducting the interview. Before signing the consent form, it was also explained to them that the work would be confidential and that the data would be used strictly for research purposes.

\section{Results}

An application, or video game, is not only built from the point of view of the designers, but also from the point of view of the people who will use it, in this case, students with dyslexia. Thus, the interviews conducted are an important starting point for the design of the activities included in the software.

In this section, an analysis is made of the information provided in the interviews by the different informing agents based on user-centered design, which considers it important to consider the opinion of the end user, in order to achieve greater acceptance on their part and avoid early abandonment.

According to the needs of students with dyslexia, the lines of development of the activities are defined, as well as the characteristics to be taken into account in the design of the application.

\subsection{Application Design: Developmental Lines}

Taking into account the various domains in which people with dyslexia present difficulties $[71,72]$ and, after the content analysis of the interviews conducted with the interest groups, ten categories were extracted in which students with dyslexia present more difficulties and, thus, require more specific work: lexical development, phonological awareness, short-term memory, perceptual-visual development, perceptual-auditory development, semantic development, motor development balance, anxiety reduction through reading, attention, and reading fluency.

These categories were subjected to expert judgment by doctors in education, dyslexia specialists, and external VR experts who have expressed their opinion and developed different proposals for the development of the software within the analyzed axes of intervention. In addition, they were also agreed upon by the consortium partners. Finally, seven lines of development were determined from which the activities that make up the virtual reality application based on a video game have been designed [73].

\subsubsection{Phonological Awareness}

Phonological awareness is that by which we come to possess our own language and consciously distinguish sequences and correspondences of letter and sound, i.e., phoneme recognition.

Therefore, reading poses a particular challenge because of the existing evidence that students with dyslexia have a particular difficulty in decoding phonemes. In this sense, to work on phonological awareness and the alphabetic principle within the software, we have 
developed activities of grapheme-phoneme relationship, syllable recognition (syllable awareness), word and pseudoword reading (lexical awareness), and phonemic awareness.

\subsubsection{Working Memory}

To read a paragraph correctly, we need to retain the beginning of a written sentence in order to understand the end. A long and complex sentence will be much more difficult to understand than a short and simple one. Working memory is therefore related to correct reading comprehension, which has also been called reading memory.

To reinforce working memory, the application proposes short-term memorization activities through selection and identification activities of letters and symbols at a visual level (association of images with quantities, association of image and number, etc.), identification of sounds, and repetition of series of letters, numbers, or words. They also work on instructions and characteristics that they must remember or memorize in order to advance in the game.

\subsubsection{Attention Development}

Attention mediates sustained memory processes for the execution of certain tasks in conscious perception, in the allocation of cognitive resources, and in the interaction with long-term memory.

Through the application, activities are carried out to work on attention and selective attention in a playful way in practically all the activities of the application. The activities are aimed at identifying differences, identifying the consonant sound that is repeated in all the words of a series, searching for the same objects in a group, narrating a story that gives clues (being able to retrieve information), and providing auditory support of texts and retrieval of information.

\subsubsection{Perceptual-Visual Development}

Visuospatial attention deficits may be associated with dyslexia, with visual discrimination and visuospatial attention being considered predictors of dyslexia.

At the perceptual-visual level, activities are carried out to recognize words within a text: reading incomplete words, activities to find the differences, continuing a visual series from a model, etc.

\subsubsection{Perceptual-Auditory Development}

Struggling readers tend to show auditory-phonological processing deficits in syllable discrimination tasks when they are pre-readers.

For perceptual-auditory development, the software activities include exercises for identifying sounds in words, the first and last sounds in a word, words that begin with the same sound, etc.

\subsubsection{Semantic, Syntactic and Lexical Development}

Reading is an apparently fast activity; it demands automatisms and the performance of a series of mental operations until reaching the meaning and pronunciation of written words. Likewise, it is linked to three processes of interaction between the reading subject and the text: first, to the phonological in the transduction of grapheme to phoneme; second, to the identification of the word in relation to its respective meaning; and finally, to the comprehension of the meaning of the text.

Within the semantic development, some of the activities will be geared towards word and sentence comprehension, reading aloud, and plot comprehension.

The lexical development will be worked on through activities with pseudowords, as it is an added difficulty since the application will be generated in the three languages of the project partners. The work through the pseudoword technique is endorsed among dyslexia specialists as a useful method of work and treatment [74]. 


\subsubsection{Motor Development: Laterality and Directionality}

Students with dyslexia show impaired motor development, with inferior skills in global motor function, balance, spatial organization, and temporal organization.

For this reason, activities will be performed to work in the area of motor development and will be related to visual-motor coordination (pointing and shooting with the pointer, moving pieces by dragging with the finger, moving figures, and hitting the right one), balance (avoiding obstacles), and spatial orientation.

\subsection{Application Design: Characteristics}

The results obtained from the interviews conducted with students with dyslexia have contributed to determining the aesthetic and technical aspects of the configuration of the application such as scenarios, displacements, customization, or game mechanics.

\subsubsection{Essential Elements}

They consider that the game must have a series of essential elements, among which they highlight aspects such as sound and image quality, showing a clear preference for colorful scenes.

They believe that customization is essential, above all, with regard to the possibility of choosing characters and accessories, which would be obtained and discovered as the game progresses and different challenges and levels are overcome. That is to say, the surprise factor is implicit.

\subsubsection{Spaces and Scenarios}

In relation to the spaces and scenarios in which to develop the game, they propose very open environments such as other planets or dimensions and large cities.

They have also requested an environment that is as realistic as possible. In this sense, it seems reasonable to look for environments that can be realistic so that the transfer of what has been worked on to their day-to-day performance can be as simple as possible. In this sense, the possibility of the scenario reflecting an educational center was suggested, thinking that it would be a treatment environment as close to reality as possible, but the majority response was rejection.

However, one of the interviewees understood that it would be acceptable for the game to take place at school as long as it was not related to homework and there was the possibility of leaving the school to explore other environments.

\subsubsection{Actions}

Participants have shown a clear preference for a non-linear development of the game; however, there is no agreement on the scenarios or environments in which to develop the application. They prefer a scenario in which they can move freely and in which they can discover new things. That is, they state that they would like to be able to have freedom of movement throughout the game environment, being able to use different types of vehicles to move around.

Participants show their preference for the possibility of combining fast actions, action activities, and intrigue with more relaxed actions.

\subsubsection{Usability}

From the point of view of usability, they have indicated that for them it is very important that the game is not excessively difficult, especially if progress requires investing many hours or performing a series of repetitive actions many times.

Another important recommendation, which may affect the difficulty of the game, has to do with the way in which the instructions are presented. In this sense, they have stated that it is very difficult for them to follow the instructions when they are in another language and, above all, when they are only provided in written form. 


\subsubsection{Proposals to Include}

They propose that within the game there should be different types of activities and different challenges, intrigues, etc., in which there is the possibility of carrying out quick actions as well as more relaxed ones.

They require that the game allows them to live another reality in which they can escape and forget about everything while playing. Being able to choose a role and express themselves in a different world could motivate them to follow the treatment by playing that desired/chosen role [75].

In relation to the elements to be included, they highlighted creativity, the possibility of creating their own levels, and open worlds that are faithful to reality and that include a short and precise video tutorial.

\subsection{Application Development}

\subsubsection{Game Structure}

To define the main elements of the game, as well as the relationships between them, we have taken into account the "pyramid of the elements" of Werbach and Hunter [76,77], who grouped the game elements based on the principle of progression, that is, the lower levels constitute the path to access the elements of a higher level, evolving from the simplest and most obvious to the most complex and abstract.

This model understands that the most important thing in a game is at the top of the pyramid and is called "dynamics". In order to create these dynamics, we need the elements of the lower level, which are the "mechanics", which, in turn, require the base of the pyramid: the "components".

In line with this proposal, the MDA model (mechanics, dynamics, and aesthetics) has also been followed in the development of the application. This game design and adjustment framework is based on the three basic elements that a game must have: mechanics, dynamics, and aesthetics [76].

Taking into account these proposals, the development of the application understood as a game has been carried out. This section summarizes the most relevant aspects that make up the structure of the virtual reality game.

The environment of the game has been decided to be a planetary environment, with different scenarios configured around four planets that are identified with landscapes related to reality: urban, desert, mountainous, and marine. Therefore, the environment is a universe where the user must travel between the different planets. All this follows the contributions of the interviewees in relation to generating a more dynamic game that is as real as possible, including a quality ambient sound.

Therefore, the game consists of four levels, configured in four planets, and, in each one of them, there is a power crystal, it being necessary to find all the crystals to recompose the planet Earth. Figure 2 shows images of the different planets that make up the game environment.

Regarding the characters, the main character of the game is a robot called "Wibu", who is in charge of explaining the activities and helping the player to overcome each test. On the other hand, on each planet, there is a character associated with it that will interact with the player during the different missions.

Bearing in mind that one of the essential aspects for users is personalization, the game allows them to select an avatar (graphic representation associated with the player for identification purposes) from among various options.

In relation to the game mechanics, understood as the actions that a player can perform, as well as the rules by which they interact, the game begins in a spaceship, which constitutes the center of operations where the necessary instructions will be given to start the game. 


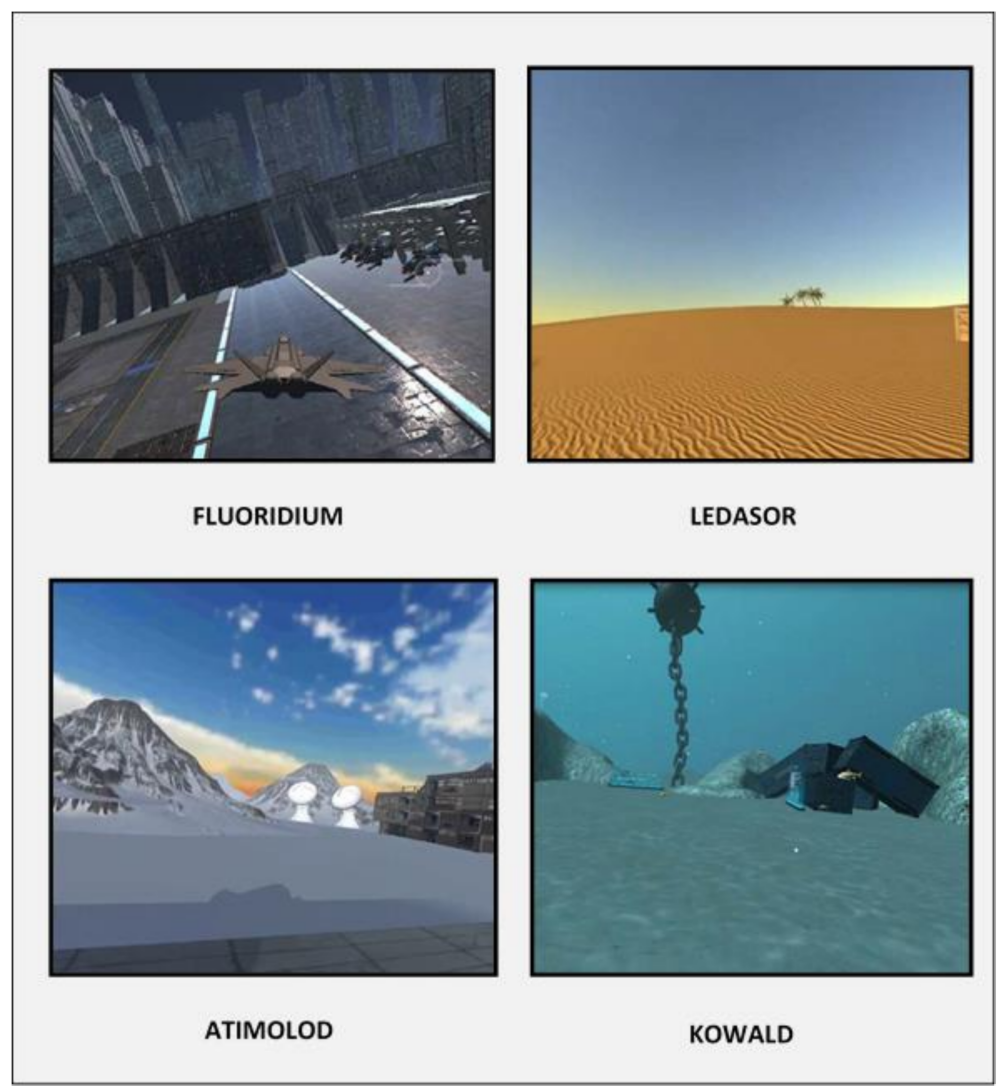

Figure 2. Images of the different planets that make up the game environment.

As can be seen in Figure 3, in the operations center, there is a control screen where the different planets that make up the four levels of the game are shown. Below the planets are the different avatars that the player can select.

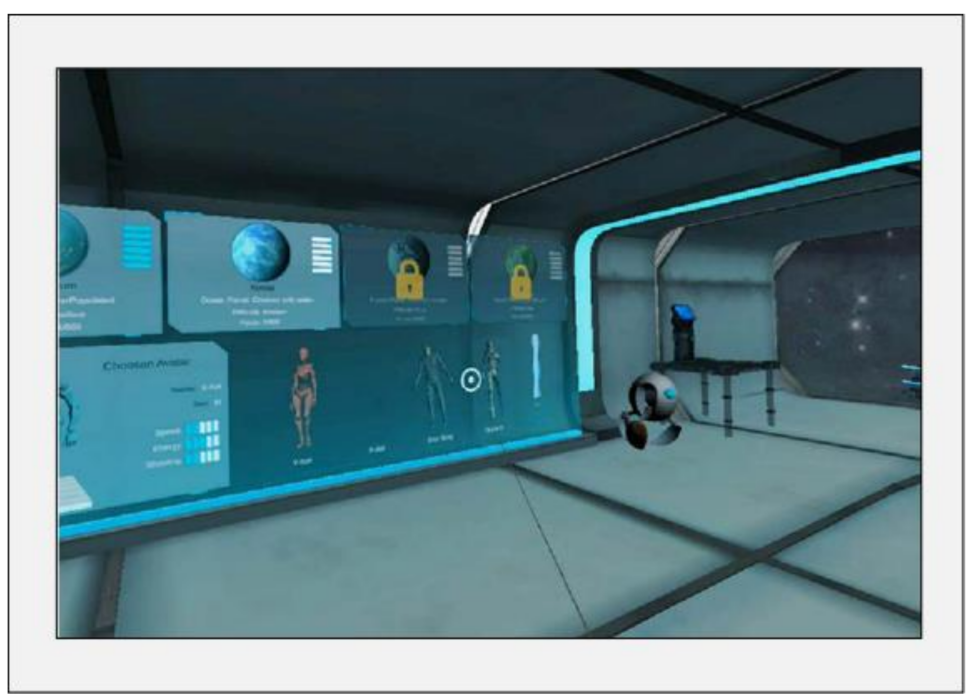

Figure 3. Image of the operations center.

Interplanetary travel is done from the central ship with a stellar vehicle, for which the players must perform a first activity to obtain the license that allows them to travel around the different planets.

Once the license is obtained, from the operations center, with the stellar vehicle, the player can access each of the planets that make up the game. After opening the hatch of the 
central ship, it is possible to access the universe and travel to the different planets. When the users approach a planet, they will see a fading effect; the screen turns black, and the spaceship lands on it. Afterward, the user will be inside the planet and will be able to move freely through space to perform the different activities.

In order to advance and unlock the different levels, it is necessary to complete the missions that arise on each planet, corresponding to different activities where the lines of development in the treatment of dyslexia identified and agreed upon by the experts consulted are worked on. After successfully completing the activities, the player obtains fragments of the power crystal that must be assembled in a final activity to save the inhabitants of each planet.

In relation to the dynamics, the aim is to encourage the players' motivation. To this end, after each activity, a certain medal (gold, silver, or bronze) is assigned according to the number of correct scores and the time in which it was completed. In order to deactivate the different levels, players will be required to obtain a minimum score in the activities.

\subsubsection{Activities}

The activities included in the application have been designed using a multisensory approach, following the neurobiological approach to dyslexia, given the promising results of the same and the increased adherence to treatment.

The design of the virtual reality video game activities has been carried out considering the seven lines of development extracted in the first phase of the research [73], which represent the various areas in which people with dyslexia have difficulties.

At first, the work team formed by pedagogues, doctors in education, and experts in dyslexia made an initial proposal of activities that was sent to the software developer company. After its study by all the project partners as well as the adaptation to the available budget, a total of eight activities have been designed for the application, some of which are repeated in the different planets varying their difficulty. In this way, the player will develop the necessary skills to overcome the activities without getting frustrated.

Rewards are allocated based on correct answers and time of completion.

As an example, Figure 4 shows an image of "Activity 0", which is thus named because it is necessary to perform and pass this activity in order to obtain the star motorcycle license that allows moving around each of the planets that make up the universe of the video game. Specifically, this activity is related to the following lines: visual perceptual development, auditory perceptual development, and motor development.

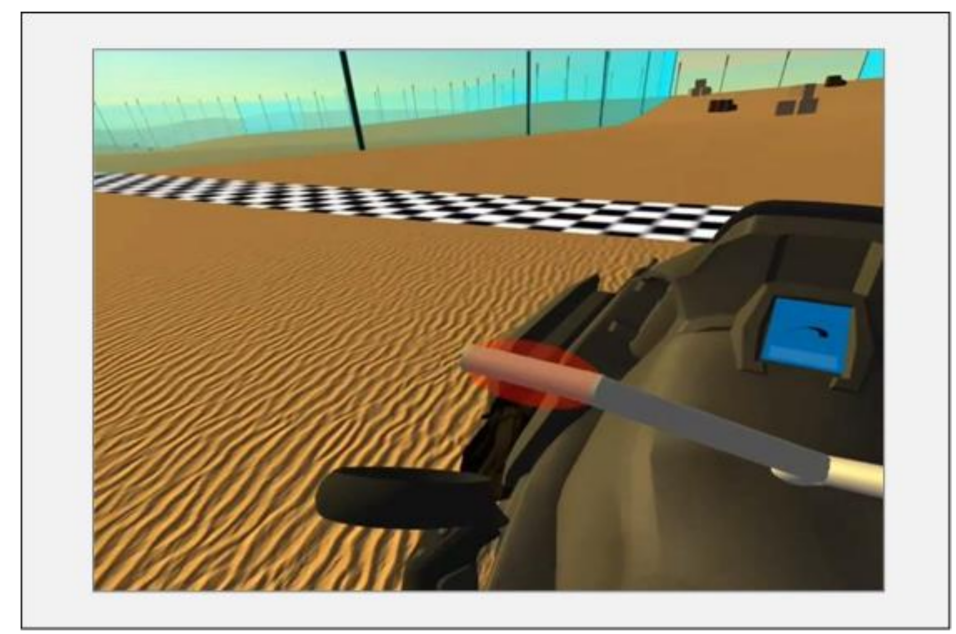

Figure 4. Image of the "Activity 0". 


\section{Software Development}

Prior to the development of the software, the selection of the necessary hardware for this immersive virtual reality application was carried out, specifically the virtual reality glasses. After studying different options and reaching a consensus with the rest of the partners, the Oculus Quest Virtual Reality viewer [78], which includes the Oculus Touch controllers, was chosen. These virtual reality glasses have great processing capacity and include the Oculus Insight system, with integrated sensors that transfer movements to virtual reality and allow room-scale tracking.

In addition, the controllers allow better activities to be implemented as each controller refers to the user's position and gestures with intuitive and realistic precision.

Regarding the age of use, the recommendations of the selected hardware (Oculus Quest Virtual Reality viewer) indicate that it should not be used by children under 13 years of age, since the VR glasses do not have the appropriate dimensions for a child and may cause discomfort or health effects, as they are in a critical period in their visual development. For this reason, the design of the software has been adapted to the age range of 13 to 16 years.

Focusing on the development of the software, as explained above, the user-centered design methodology has been followed, developing its first two phases: analysis of user needs through interviews with information agents and design of activities to be included in the virtual reality application.

Once the game structure and activities were designed, Arsoft (video game developer and partner of the Project) developed the beta version of the virtual reality application in English. The prototype of the English application was tested to detect errors and propose improvements.

In order to create the different versions of the application in the different partner countries of the consortium, the translation of the textual narrative was requested, as well as the recording of audio recordings in the different languages: English, Spanish, Italian, and Romanian.

On FORDYSVAR's YouTube channel (http:/ / bit.ly/YouTube_FORDYSVAR (accessed on 24 July 2021), you can see audiovisual fragments of the software in virtual reality and augmented reality: https:/ / youtu.be/5mZYvuiuU64 (accessed on 24 July 2021).

\section{Conclusions}

The development of VR in an educational and recreational context is also incipient in scientific research, although initiatives along these lines are beginning to appear [79], although little research has been done so far. Specifically, immersive virtual reality based on the use of mobile digital devices is still in its infancy, and much progress remains to be made in its application for it to be more widely implemented. Therefore, in order to lay a solid foundation for the treatment and rehabilitation of people with dyslexia through virtual reality (VR), more scientific studies are needed to support the effectiveness of these interventions.

The European project Erasmus+ FORDYSVAR (Fostering inclusive learning for children with dyslexia in Europe by providing easy-to-use virtual and/or augmented reality tools and guidelines) arises as a complementary response to the treatment of dyslexia, being one of the first technological attempts to use virtual reality to contribute to the learning of these students.

The virtual reality application in video game format has been designed and developed under a ludic approach and not as a rehabilitative therapy that allows dispensing with the intervention of a professional specialist in dyslexia since it is configured as a complementary material that can be used by students with and without reading difficulties.

User-centered design (UCD) has been chosen as a three-phase methodology since it is essential to involve people in its design and development in order to achieve greater commitment and guarantees in its use. Technology designers support this line of work and demand greater use of co-design with end users [80]. This increases user engagement, 
facilitates the users' learning, and ensures that the technology is in line with the users' needs [81-83].

This contribution presents the results of the research carried out using the UCD as a methodology, developing its first two phases (identification of the characteristics and lines of development/design and development of the VR application), being aware of the need to address the third phase, related to the evaluation of the software designed and developed. This phase is currently being elaborated by the work team. This last phase will involve both users and stakeholders who have participated in the various phases of the design and development of the virtual reality application, where the evaluation of the reliability and validity of the instruments, as well as the effectiveness of the developed application, will be carried out later.

After the research carried out and the results obtained, it is concluded that the main contributions of this work, derived from the analysis of users' needs and interests, are the definition of the lines of development that should be worked on in dyslexia, the determination of the most relevant features that the application should include in the game format to make it attractive and motivating, and the development of VR software to improve learning in students with dyslexia. In addition, in order to offer an adequate educational response to students with dyslexia, the collaboration of the school, family, and social context, agents that must be part of the decision-making process, is necessary, with the aim of achieving changes that make it possible to improve the situation. On the other hand, technology can show us another avenue of treatment by offering alternatives for students with dyslexia who do not adapt to traditional intervention [84].

Due to all of these reasons, we believe that the work carried out within the European project Erasmus+ FORDYSVAR can contribute to the advancement of inclusion, treatment, and rehabilitation of people with dyslexia through technology and specifically through virtual reality, enabling an immersive and attractive environment to develop the skills of students with dyslexia, becoming the first virtual reality game with an inclusive approach whose development has been carried out based on the contributions of users as well as by collecting the most used lines of intervention in the intervention process of children with this learning difficulty.

However, from the work team, we believe it is necessary to continue advancing in this field in order to give scientific support to the use of virtual reality in the diagnosis and treatment of dyslexia.

Author Contributions: Conceptualization: S.R.-C., V.D.-B., V.A.-V. and L.M.M.; Methodology: S.R.-C.; Validation: V.A.-V.; Formal analysis: V.D.-B.; Investigation: S.R.-C., V.D.-B., V.A.-V. and L.M.M.; Resources: S.R.-C., V.D.-B., V.A.-V. and L.M.M.; Data curation: V.D.-B. and S.R.-C.; Writingoriginal draft preparation: V.D.-B.; Writing—review and editing: S.R.-C., V.D.-B. and V.A.-V.; visualization: V.A.-V. and L.M.M.; Supervision: S.R.-C. and V.D.-B.; Project administration: S.R.-C.; funding acquisition: European Commission. All authors have read and agreed to the published version of the manuscript.

Funding: This work has been co-financed by the Erasmus+ program of the European Union through the 2018-1-ES01-KA201-050659 project. That of the European Commission for the preparation of this publication does not imply acceptance of its contents, which is the sole responsibility of the authors. Therefore, the Commission is not responsible for the use that may be made of the information disclosed here.

Institutional Review Board Statement: The study was conducted according to the guidelines of the Declaration of Helsinki and approved by the Ethics Committee of University of Burgos (IR 13/2020; date of approval: 19 April 2020).

Informed Consent Statement: Informed consent was obtained from all subjects involved in the study.

Data Availability Statement: Page: www.fordysvar.eu.

Acknowledgments: We want to thank the collaboration of the research participants as well as the various dyslexia associations that actively collaborate in the European FORDYSVAR project. 
Conflicts of Interest: The authors declare no conflict of interest. The funders had no role in the design of the study; in the collection, analyses, or interpretation of data; in the writing of the manuscript; or in the decision to publish the results.

\section{References}

1. UNESCO. Embracing Dyslexia-Crossing the Chasm and Saving Lives. Available online: https://bit.ly/2Vzyey2 (accessed on 13 December 2020).

2. International Dyslexia Association. Definition of Dyslexia. Available online: https://dyslexiaida.org/definition-of-dyslexia/ (accessed on 11 February 2021).

3. Lyon, G.R.; Shaywitz, S.E.; Shaywitz, B.A. A definition of dyslexia. Ann. Dyslexia 2003, 53, 1-14. [CrossRef]

4. National Institute of Neurological Disorder and Stroke. Dyslexia Information Page. Available online: http://bit.ly/2IoXY8H (accessed on 10 November 2020).

5. World Health Organization. Guía de Bolsillo de la Clasificación CIE-10: Clasificación de los Trastornos Mentales y del Comportamiento; Editorial Médica Panamericana: Madrid, Spain, 2000.

6. Arlington, V.A. Diagnostic and Statistical Manual of Mental Disorders, 5th ed.; American Psychiatric Association: Washington, DC, USA, 2013.

7. Peterson, R.L.; Pennington, B.F. Developmental dyslexia. Lancet 2012, 379, 1997-2007. [CrossRef]

8. Benítez-Burraco, A. Neurobiología y neurogenética de la dislexia. Neurología 2010, 25, 563-581. [CrossRef]

9. Cidrim, L.; Madeiro, F. Information and Communication Technology (ICT) applied to dyslexia: Literature review. Rev. CEFAC 2017, 19, 99-108. [CrossRef]

10. International Dyslexia Association. Dyslexia at a Glance. Available online: https://dyslexiaida.org/dyslexia-at-a-glance/ (accessed on 22 January 2021).

11. Lohvansuu, K.; Torppa, M.; Ahonen, T.; Eklund, K.; Hämäläinen, J.A.; Leppänen, P.H.T.; Lyytinen, H. Unveiling the Mysteries of Dyslexia-Lessons Learned from the Prospective Jyväskylä Longitudinal Study of Dyslexia. Brain Sci. 2021, 11, 427. [CrossRef] [PubMed]

12. Artigas-Pallarés, J. Dislexia: Enfermedad, trastorno o algo distinto. Rev. Neurol. 2009, 48, 63-69. [CrossRef]

13. Jiménez, J.E.; Guzmán, R.; Rodríguez, C.; Artiles, C. Prevalencia de las dificultades específicas de aprendizaje: La dislexia en español. An. Psicol. 2009, 25, 78-85.

14. Birsh, J.R. Connecting Research and Practice. Multisensory Teaching of Basic Language Skills, 3rd ed.; Birsh, J.R., Paul, H., Eds.; Brookes Publishing: Baltimore, MD, USA, 2011; pp. 1-24.

15. Broadhead, M.; Zad, D.D.; Mackinnon, L.; Bacon, L. A Multisensory 3D Environment as Intervention to Aid Reading in Dyslexia: A Proposed Framework. In Proceedings of the 10th International Conference on Virtual Worlds and Games for Serious Applications, Wuzburg, Germany, 5-7 September 2018.

16. Kalyvioti, K.; Mikropoulos, T.A. Virtual Environments and Dyslexia: Review of literaure. Procedia Comput. Sci. 2014, 27, 138-147. [CrossRef]

17. Saputra, M.R.U.; Alfarozi, S.A.I.; Nugroho, K.A. LexiPal: Kinect-based application for dyslexia using multisensory approach and natural user interface. Int. J. Comput. Appl. Technol. 2018, 57, 334-342.

18. Cano, S.R.; Alonso, P.S.; Benito, V.D.; Villaverde, V.A. Evaluation of Motivational Learning Strategies for Children with Dyslexia: A FORDYSVAR Proposal for Education and Sustainable Innovation. Sustainability 2021, 13, 2666. [CrossRef]

19. Kalyvioti, K.; Mikropoulos, T.A. A virtual reality test for the identification of memory strengths of dyslexic students in Higher Education. J. Univers. Comput. Sci. 2013, 19, 2698-2721.

20. Phipps, L.; Sutherland, A.; Seale, J. Access All Areas: Disability, Technology and Learning; JISC TechDis Service and ALT: London, UK, 2002. Available online: https: / / www.bdadyslexia.org.uk/about (accessed on 22 November 2020).

21. Cuetos, F.; Defior, S.; Fernández, A.; Gallego, C.; Jiménez, J. Marco teórico de la dislexia. In La Atención al Alumnado con Dislexia en el Sistema Educativo en el Contexto de las Necesidades Específicas de Apoyo Educativo Ministerio de Educación, Cultura y Deporte (Coord.); Centro Nacional de Innovación e Investigación Educativa: Madrid, Spain, 2012; pp. 23-43.

22. Meyer, A.; Rose, D.H.; Gordon, D. Universal Design for Learning: Theory and Practice; CAST Professional Publishing: Wakefield, MA, USA, 2014.

23. Núñez, M.P.; Santamaría, M. Una propuesta de mejora de la dislexia a través del procesador de textos: "Adapro". Rev. Educ. Hekademos 2016, 19, 20-25.

24. Cidrim, L.; Braga, P.; Madeiro, F. Desembaralhando: A Mobile Application for Intervention in the Problem of Dyslexic Children Mirror Writing. Revista CEFAC 2018, 20, 13-20. [CrossRef]

25. Skiada, R.; Soroniati, E.; Gardeli, A.; Zissis, D. EasyLexia: A mobile application for children with learning difficulties. Procedia Comput. Sci. 2014, 27, 218-228. [CrossRef]

26. Suárez, A.I.; Pérez, C.Y.; Vergara, M.M.; Alférez, V.H. Desarrollo de la lectoescritura mediante TIC y recursos educativos abiertos. Apert 2015, 7, 38-49.

27. Williams, P.; Jamali, H.R.; Nicholas, D. Using ICT with people with special education needs: What the literature tells us. Aslib Proc. New Inf. Perspect. 2006, 58, 330-345. [CrossRef] 
28. Zikl, P.; Bartošová, I.K.; Víšková, K.J.; Havlíčková, K.; Kučírková, A.; Navrátilová, J.; Zetková, B. The possibilities of ICT use for compensation of difficulties with reading in pupils with dyslexia. Procedia Soc. Behav. Sci. 2015, 176, 915-922. [CrossRef]

29. Rodríguez-Cano, S.; Ausín-Villaverde, V.; Delgado-Benito, V.; Cuevas-Romero, S. Análisis de las Prácticas Educativas Utilizadas con Niños con Dislexia en el ámbito Europeo. In Proceedings of the Conferência Ibérica de Inovação na Educação com TIC I IEtic2020 Livro de Resumos, Açores, Portugal, 27-28 February 2020; Moreira, J.A., Gonçalves, V., García-Valcárcel, A., Gutiez Cuevas, P., Eds.; Instituto Politécnico de Bragança: Bragança, Portugal, 2020; pp. 60-61.

30. Aznar Díaz, I.; Romero-Rodríguez, J.M.; Rodríguez-García, A.M. La tecnología móvil de Realidad Virtual en educación: Una revisión del estado de la literatura científica en España. Edmetic Rev. Educ. Mediática Tic 2018, 7, 256-274. [CrossRef]

31. Montana, J.I.; Tuena, C.; Serino, S.; Cipresso, P.; Riva, G. Neurorehabilitation of spatial memory using virtual environments: A systematic review. J. Clin. Med. 2019, 8, 1516. [CrossRef]

32. Zeng, N.; Pope, Z.; Lee, J.E.; Gao, Z. Virtual reality exercise for anxiety and depression: A preliminary review of current research in an emerging field. J. Clin. Med. 2018, 7, 42. [CrossRef]

33. Mura, G.; Carta, M.G.; Sancassiani, F.; Machado, S.; Prosperini, L. Active exergames to improve cognitive functioning in neurological disabilities: A systematic review and meta-analysis. Eur. J. Phys. Rehabil. Med. 2018, 54, 450-462. [CrossRef]

34. Dehaene, S.; Cohen, L. The unique role of the visual word form area in Reading. Trends Cogn. Sci. 2011, 15, 254-262. [CrossRef]

35. Dehaene, S. Aprender a Leer: De las Ciencias Cognitivas al Aula; Siglo Veintiuno Editores: Buenos Aires, Argentina, 2015.

36. Ylinen, S.; Kujala, T. Neuroscience illuminating the influence of auditory or phonological intervention on language-related deficits. Front. Psychol. 2015, 6, 137. [CrossRef] [PubMed]

37. Santiuste-Bermejo, V.; Santiuste-Díaz, M. Consistencia epistémica del síndrome de dificultades del aprendizaje: Aportaciones de la magnetoencefalografía como técnica de neuroimagen funcional. Univ. Psychol. 2008, 7, 655-671.

38. Carboni Román, A.; Río Grande, D.D.; Capilla, A.; Maestú, F.; Ortiz, T. Bases neurobiológicas de las dificultades de aprendizaje. Rev. Neurol. 2006, 42, 171-175. [CrossRef]

39. Bravo Valdivieso, L. El aprendizaje del lenguaje escrito y las ciencias de la lectura: Un límite entre la psicología cognitiva, las neurociencias y la educación. Rev. Interdiscip. Filos. Psicol. 2016, 11, 50-59.

40. Dehaene, S.; Cohen, L.; Morais, J.; Kolinsky, R. Illiterate to literate: Behavioral and cerebral changes induced by reading acquisition. Nat. Rev. Neurosci. 2015, 16, 234-244. [CrossRef] [PubMed]

41. Galaburda, A.; LoTurco, J.; Ramus, F.R.; Fitch, h.; Rosen, G.D. La Dislexia del Desarrollo: Gen, Cerebro y Cognición. Psykhe 2006, 15, 3-11. [CrossRef]

42. Rosselli, M.; Matute, A. Desarrollo cognitivo y maduración cerebral. In Neuropsicología del Desarrollo Infantil; Manual Moderno: Ciudad de México, Mexico, 2010; pp. 15-46.

43. Román, M.; Cardemil, C.; Carrasco, A. Enfoque y metodología para evaluar la calidad del proceso pedagógico que incorpora TIC en el aula. Rev. Iberoaméricana Evaluación Educ. 2011, 4, 9-35.

44. Pazmiño, A.; Jácome, J.; Santillán, C.; Freire, M. El uso de las TIC para el aprendizaje de la programación. Dominio Cienc. 2019, 5, 290-298. [CrossRef]

45. Stevens, C. Information and Communication Technology, Special Educational Needs and Schools: A Historical Perspective of UK Government Initiatives. ICT and Special Educational Needs: A Tool for Inclusion; Open University Press: Buckingham, UK, 2004.

46. Bertoni, S.; Franceschini, S.; Puccio, G.; Mancarella, M.; Gori, S.; Facoetti, A. Action Video Games Enhance Attentional Control and Phonological Decoding in Children with Developmental Dyslexia. Brain Sci. 2021, 11, 171. [CrossRef]

47. Dyson, A.; Farrell, P.; Polat, F.; Hutcheson, G.; Gallanaugh, F. Inclusion and Pupil Achievement; Department for Education and Skills: London, UK, 2004.

48. Rodríguez, C.; Jiménez, J.E.; Díaz, A.; González, D. Tradislexia: Un videojuego para la mejora de la lectura en niños con dislexia. Nuevas Tend. TIC Educ. 2011, 1, 122-134.

49. Núñez, M.P.; Santamaría, M. Prerrequisitos para el proceso de aprendizaje de la lectura y la escritura: Conciencia fonológica y destrezas orales de la lengua. Lengua Habla 2014, 18, 72-92.

50. Bautista-Vallejo, J.M.; Hernández-Carrera, R.; Moreno-Rodríguez, R.; López-Bastias, J.L. Improvement of Memory and Motivation in Language Learning in Primary Education through the Interactive Digital Whiteboard (IDW): The Future in a Post-Pandemic Period. Sustanability 2020, 12, 8109. [CrossRef]

51. Mikropoulos, T.A.; Strouboulis, V. Factors That Influence Presence in Educational Virtual Environments. Cyberpsychol. Behav. 2004, 7, 582-591. [CrossRef]

52. Moreno, N.M.; Leiva, J.J.; Galván, M.C.; López, E.; García, F.J. Realidad aumentada y realidad virtual para la enseñanzaaprendizaje del inglés desde un enfoque comunicativo e intercultural. In Innovación Docente y Uso de las TIC en Educación; Málaga, UMA Editorial: Malaga, Spain, 2017; pp. 1-11.

53. Otero, A.; Flores, J. Realidad virtual: Un medio de comunicación de contenidos. Aplicación como herramienta educativa y factores de diseño e implantación en museos y espacios públicos. Icono 14 Rev. Comun. Audiov. Nuevas Tecnol. 2011, 9, $185-211$.

54. Cuesta, U.; Mañas, L. Integración de la realidad virtual inmersiva en los Grados de Comunicación. Icono 14 Rev. Comun. Audiov. Nuevas Tecnol. 2016, 14, 1-21. [CrossRef]

55. Stanmore, E.; Stubbs, B.; Vancampfort, D.; de Bruin, E.D.; Firth, J. The effect of active video games on cognitive functioning in clinical and nonclinical populations: A meta-analysis of randomized controlled trials. Neurosci. Biobehav. Rev. 2017, $78,34-43$. [CrossRef] 
56. Jin, R.; Pilozzi, A.; Huang, X. Current Cognition Tests, Potential Virtual Reality Applications, and Serious Games in Cognitive Assessment and Non-Pharmacological Therapy for Neurocognitive Disorders. J. Clin. Med. 2020, 9, 3287. [CrossRef]

57. Ausín, V.; Delgado, V.; Cuevas, S.; Santaolalla, G.; Bortolot, S.; Flego, L.; Ioan, A.; Ibars, V. Nuevas Tendencias en el Tratamiento de la Dislexia: Utilización de la Realidad Virtual. In Proceedings of the I Congreso Internacional Educación Crítica e Inclusiva, Universidad de León, León, Spain, 27-28 September 2019.

58. FORDYSVAR. Objetivos y Destinatarios. Fostering Inclusive Learning for Children with Dyslexia in Europe by Providing Easy-toUse Virtual and/or Augmented Reality Tools and Guidelines. Available online: https://fordysvar.eu/es/proyecto/objetivos-ydestinatarios (accessed on 14 December 2020).

59. De la Peña, C. Revisión de programas de intervención en Dislexia Evolutiva. Reidocrea 2016, 5, 310-315.

60. Hernández, R.; Fernández, C.; Baptista, P. Metodología de la Investigación; Editorial McGraw Hill: Ciudad de Mexico, México, 2010.

61. Herrera, C.D. Investigación cualitativa y análisis de contenido temático. Orientación intelectual de revista Universum. Rev. Gen. Inf. Doc. 2018, 28, 119-142.

62. Ruíz, J. Metodología de la Investigación Cualitativa; Universidad de Deusto: Bilbao, Spain, 2012.

63. Maguire, M. Methods to support human-centred design. Int. J. Hum. Comput. Stud. 2001, 55, 587-634. [CrossRef]

64. Rubio, G.; Navarro, E.; Montero, F. APADYT: A multimedia application for SEN learners. Multimed. Tools Appl. 2014, 71, 1771-1802. [CrossRef]

65. Design Toolkit. Diseño Centrado en las Personas. Universitat Oberta de Catalunya. Available online: http:/ / design-toolkittest.uoc. edu/es/diseno-centrado-en-las-personas/ (accessed on 15 November 2020).

66. Cuevas, S. Propuesta de Intervención para Alumnado con Dislexia a Través de la Realidad Virtual. Master's Final Project. Master's Degree, Universidad de Burgos, Burgos, Spain, 2019.

67. Martín, R.M. Estadística y Metodología de la Investigación: Análisis de Contenido; Universidad de Castilla-La Mancha, Ciudad de Real, Spain. 2015. Available online: https:/ / previa.uclm.es/profesorado/raulmmartin/Estadistica_Comunicacion/AN\%C3 \%81LISIS\%20DE\%20CONTENIDO.pdf (accessed on 10 November 2020).

68. Arbeláez, M.; Onrubia, J. Análisis bibliométrico y de contenido. Dos metodologías complementarias para el análisis de la revista colombiana Educación y Cultura. Revista Investig. UCM 2014, 14, 14-31. [CrossRef]

69. Sabariego, M.; Dorio, I.; Massot, I. Metodología de la investigación educativa. Metodología de Cualitativa; Bisquerra, R., Ed.; La Muralla: Madrid, Spain, 2004; pp. 276-366.

70. Cuevas, S.; Abella, V.; Ausín, V.; Delgado, V. Elementos claves en el diseño de una intervención en RV para el tratamiento de la dislexia: La perspectiva de los usuarios. In Jornadas Universitarias de Tecnología Educativa, Libro de Actas, XXVII ed.; Universidad de Cantabria: Santander, Spain, 2019.

71. Fletcher, J.M.; Lyon, G.R.; Fuchs, L.S.; Barnes, M.A. Learning Disabilities: From Identification to Intervention; The Guildfor Press: New York, NY, USA, 2019.

72. National Reading Panel. Teaching Children to Read: An Evidence-Based Assessment of The Scientific Research Literature on Reading and Its Implications for Reading Instruction: Reports of The Subgroups; National Institute of Child Health and Human Development: Washington, DC, USA, 2000.

73. Rodríguez-Cano, S.; Ausín-Villaverde, V.; Delgado-Benito, V.; Tuñón-De Hoyos, M. Líneas de intervención para el diseño de toolkit en el proyecto FORDYSVAR. In V Encontro International de Formação na Docência: Livro de Resumos; Instituto Politécnico de Bragança: Bragança, Portugal, 2020.

74. Aguado, G.; Ripoll, J.C.; Tapia, M.M.; Gibson, M. Marcadores de trastorno específico del lenguaje en español: Comparación entre la repetición de oraciones y la repetición de pseudopalabras. Rev. Logop Foniatría Audiol. 2018, 38, 105-112. [CrossRef]

75. Kusuma, G.P.; Wigati, E.K.; Utomo, Y.; Suryapranata, L.K.P. Analysis of Gamification Models in Education Using MDA Framework. Proc. Comput. Sci. 2018, 135, 385-392. [CrossRef]

76. Werbach, K.; Hunter, D. For the Win: How Game Thinking Can Revolutionize Your Business; Wharton School Press: Philadelphia, PA, USA, 2012.

77. Hunicke, R.; LeBlanc, M.; Zubek, R. MDA: A formal approach to game design and game research. In Proceedings of the AAAI Workshop on Challenges in Game AI, San Jose, CA, USA, 25-26 July 2004; Volume 4, p. 1722.

78. Oculus Oculus Quest. 2020. Available online: https://www.oculus.com/quest/?locale=es_ES (accessed on 15 December 2020).

79. Attree, E.; Turner, M.J.; Cowel, N. A virtual reality test identifies the visuospatial strenghts of adolescents with dyslexia. Ciberpsychol. Behav. 2009, 12, 163-168. [CrossRef]

80. Sanders, E.B.; Stappers, P.J. Co-creation and the new landscapes of design. CoDesign Int. J. CoCreat. Des. Arts 2008, 4, 5-18. [CrossRef]

81. Muller, M.J. Participatory design: The third space in HCI. In The Human-Computer Interaction Handbook; L. Erlbaum Associates Inc.: Hillsdale, NJ, USA, 2003; pp. 1051-1068.

82. Vines, J.; Clarke, R.; Wright, P.; McCarthy, J.; Olivier, P. Configuring participation: On how we involve people in design. In Proceedings of the SIGCHI Conference on Human Factors in Computing Systems, CHI'13, New York, NY, USA, 27 April-2 May 2013; pp. 429-438. 
83. Howard, P.A.; Hodder, S.G. Characteristics of habituation to motion in a virtual environment. Displays 2008, 29, 117-123. [CrossRef]

84. Caldani, S.; Gerard, C.-L.; Peyre, H.; Pia Bucci, M. Visual Attentional Training Improves Reading Capabilities in Children with Dyslexia: An Eye Tracker Study During a Reading Task. Brain Sci. 2020, 10, 558. [CrossRef] [PubMed] 